\title{
Exacerbation of cGVHD
}

National Cancer Institute

\section{Source}

National Cancer Institute. Exacerbation of CGVHD. NCI Thesaurus. Code C103143.

A worsening of chronic Graft versus Host Disease (cGVHD) manifestations during withdrawal of immunosuppressive therapy which does not exceed those at the beginning of the trial and improves after reinstatement of previous treatment. 